\title{
Pattern and practice of psychoactive substance abuse and risky behaviours among street children in Cameroon
}

\author{
S Cumber, MA, MPH, BA; J Tsoka-Gwegweni, PhD, MPH, MSc, BA, BSc \\ Public Health Medicine, School of Nursing and Public Health, University of KwaZulu-Natal, Durban, South Africa
}

Corresponding author: J Tsoka-Gwegweni (tsokagwegweni@ukzn.ac.za)

\begin{abstract}
Background. Cameroon is among other developing countries reported to be facing an increasing problem of street children involved in drug abuse and other harmful behaviours. Although there are some government efforts to intervene, little is known about the extent of psychoactive substance abuse and the related behaviours among street children in Cameroon. The information is critical to support policy formulation and the implementation of interventions to tackle this problem.

Objective. To document the pattern and practice of psychoactive substance abuse and the related risky behaviours among street children in three cities in Cameroon.

Methods. This study was an analytical cross-sectional survey conducted by the administration of questionnaires to 399 street children who had been homeless for at least a month in three cities of Cameroon during 2015.

Results. All 399 participants reported that they were using some psychoactive substance at the time of the survey. The preferred substances were alcohol (45.9\%), tobacco $(28.8 \%)$, volatiles $(11.5 \%)$ and cannabis $(10.3 \%)$. Girls were more predisposed to sex work for survival than boys $(p<0.000)$, with the majority of the participants reporting to have had unprotected sex after using any drug or consuming alcohol (93.98\%). In most cases, the pattern and practice of psychoactive substance abuse were higher in the cities of Douala and Yaoundé than in Bamenda. The participants reported that the substances were readily available from street vendors.

Conclusion. The results revealed that the level of psychoactive substance abuse is very high among street children, especially boys, in all three cities. Efforts to prevent and rehabilitate street children from abusing psychoactive substances are required. The government, roleplayers, decision-makers, the ministry of trade and industry and all stakeholders working with street children should consider working together in order to improve the quality of life for street children in Cameroon.
\end{abstract}

S Afr J Child Health 2016;10(3):166-170. DOI:10.7196/SAJCH.2016.v10i3.1066

Millions of children around the world live on the streets and are being exposed to harmful psychoactive substances. Their right to education, shelter, food, hygiene, healthcare and a loving family has been violated. ${ }^{[1]}$ Street children are defined by the United Nations Children's Fund (UNICEF) as children in difficult circumstances. ${ }^{[2]}$ However in this study, a street child will be defined as any boy or girl below the age of 18 years, who has taken to the streets (including unoccupied dwellings, wastelands and unfinished buildings) as their habitual abode and source of their livelihood. Although the global estimate of the number of street children is unknown, the existing estimates by UNICEF suggest that there are tens of millions of streetbased children, and $\sim 90 \%$ are found in low- and middle-income countries (LMICs). ${ }^{[2,3]}$ Estimates of the prevalence of street children are available in some countries: Ethiopia has over 150 000, Kenya over 300 000, Egypt over 1 million, Bangladesh over 400 000, Latin America over 7 million and Russia has over 16000 children working on the urban streets. ${ }^{[4,5]}$ Street children are exposed to a number of risks and are more likely to face physical, emotional and sexual abuse, especially at night. There is the risk of unwanted pregnancy, HIV and other sexually transmitted diseases (STDs), from either sexual abuse or from having engaged in risky sexual activities and prostitution. They often fall sick owing to the harsh cold weather, poor hygiene and sanitation, malnutrition and risk of accidents. Selling or abusing drugs or becoming involved in gang or criminal activities might land them in prison. ${ }^{[4,0-9]}$ Drug use is often characterised by the polydrug use of inexpensive and accessible drugs such as alcohol, tobacco, cannabis and volatiles such as glue, benzene and solvents. These drugs are harmful and even deadly for children below the age of 18 years. ${ }^{[4,10]}$ The long-term effects of solvent abuse include sudden death, respiratory depression as well as chronic neurological, pulmonary and hepatic toxicity. ${ }^{[3,5]}$ Psychoactive substances are available from roadside traders and sold to minors at a low cost. Although selling drugs to minors is a crime punishable by law in most countries, implementation of the law is often absent. It has been reported that there is a higher prevalence of psychoactive substance abuse among street boys than girls. ${ }^{[11,12]}$ These substances are commonly being consumed by drinking, smoking, sniffing and injecting. Some studies have reported that children abuse these substances to help them cope with the harsh situation on the streets and to give them courage to become involved in risky activities. ${ }^{[13,14]}$ Other studies in Africa have shown that the longer these children are left on the streets, the more frequently they abuse different substances. After a period of time they are more likely to become addicted to these substances. ${ }^{[4,14]}$ Cameroon is one of the many LMICs experiencing an increase in the number of street children living in the major cities ${ }^{[4,9,13]}$ Government authorities are concerned with the problem of psychoactive substance abuse by these children in Cameroon, yet efforts to implement the intervention process have been slow. Comments from the ministry of children and women affairs state that the ministry has been unable to assess the exact situation and intervene because of insufficient information about the problem. ${ }^{[4,9]}$ The lack of data on the pattern and practice of psychoactive substance abuse and risky behaviours among street children in Cameroon has been the main reason for this study.

\section{Method}

An analytical cross-sectional survey of street children aged 12 17 years was conducted from 1 January to 30 March 2015 in the three cities in Cameroon known to have large numbers of street children. 
The children were recruited using snowball sampling. ${ }^{[4,9]}$ Informed consent was obtained by the primary researcher using the language in which the children were most comfortable (English, French or a local language). Consent was obtained from all participants in all three cities. Participants had to understand the requirements of the study before signing the consent form. No names were written on the questionnaire and only the authors had access to the data collected. The Catholic Church provided a private, quiet location where the questionnaires were administered with the assistance of six trained research assistants. This was necessary as some of the participants could not read and write. After the interviews, refreshments were given to the participants and other street children who happened to be around, but no monetary incentive was provided.

Approval to conduct the survey was granted by the University of KwaZulu-Natal Biomedical Research Ethics Committee (ref.: BE331/14) and the Cameroon Bioethics Initiative (ref.: CB1/309/ERCC/CAMBIN).

Questions asked included demographic details, use and names of substances, age at first use of substances, reasons for engaging in the use of the substances, source and person who introduced the child to use substances, the method of ingestion, and involvement in sexual, risky and violent behaviours following use of these substances. After collection and cleaning, data were captured in a Microsoft Excel spreadsheet (2010; USA) and imported into SPSS statistical package version 19 for windows (IBM Corp., USA) for analysis. Descriptive statistics such as frequency distributions and cross-tabulations were both used to summarise the data. A $\chi^{2}$ test of association was used to assess whether there was any association between region and other categorical variables related to substance use. All the $\chi^{2}$ tests were conducted at $5 \%$ significance level.

\section{Results}

There were 399 participants who responded to questions on substance abuse in this study. Of these, 125 (13.4\%) were from Bamenda, 137 (34.3\%) from Doula and 137 (34.3\%) from Yaoundé (Table 1). Approximately fourfifths $(80.2 \%)$ of the participants were boys. The mean (standard deviation (SD)) age of study population was 15.4 years $(1.1) ; 310$ $(77.7 \%)$ were $12-14$ years and $89(22.3 \%)$ were 15 - 17 years (Table 1).

All 399 participants indicated that they were using some type of psychoactive substance at the time of the survey (Table 1). In the study population, the type of psychoactive substance was as follows: alcohol (45.9\%) was the most consumed substance, followed by tobacco $(28.8 \%)$, then volatile liquids (11.5\%) and cannabis (10.3\%) (Fig. 1). When comparing psychoactive substance use by gender, boys reported alcohol (46.9\%) and volatiles (11.5\%) as their favourite substances, while girls preferred tobacco and cannabis (Fig. 2). The gender differences were not statistically significant $(p<0.4699)$.

\section{Regional comparisons of the pattern and practice of psychoactive substance use}

All the participants admitted to having used a psychoactive substance at one point in their life since their being on the streets. The reasons given for their first use of psychoactive substances were: curiosity (52.6\%); peer pressure $(27.8 \%)$ and emotional problems (19.6\%) (Table 2). A similar pattern was observed in each of the three regions. Although clear differences were observed between the overall reasons cited

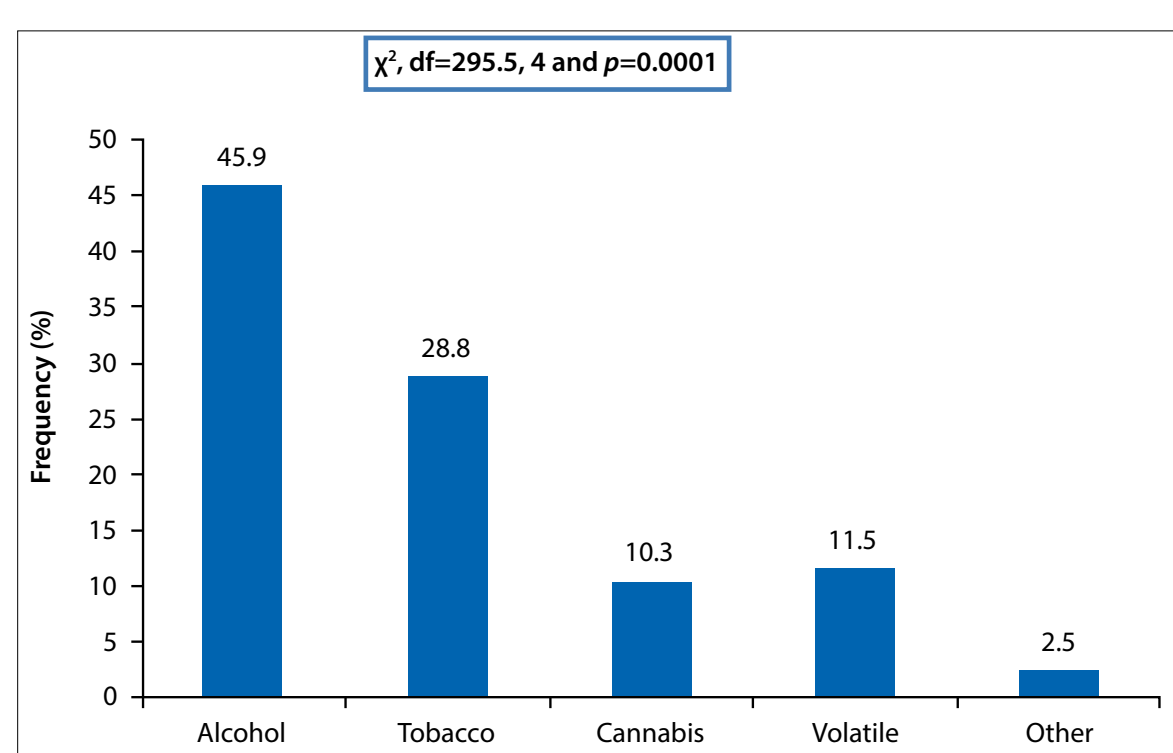

Fig. 1. Distribution of preferred psychotic substances used by respondents.

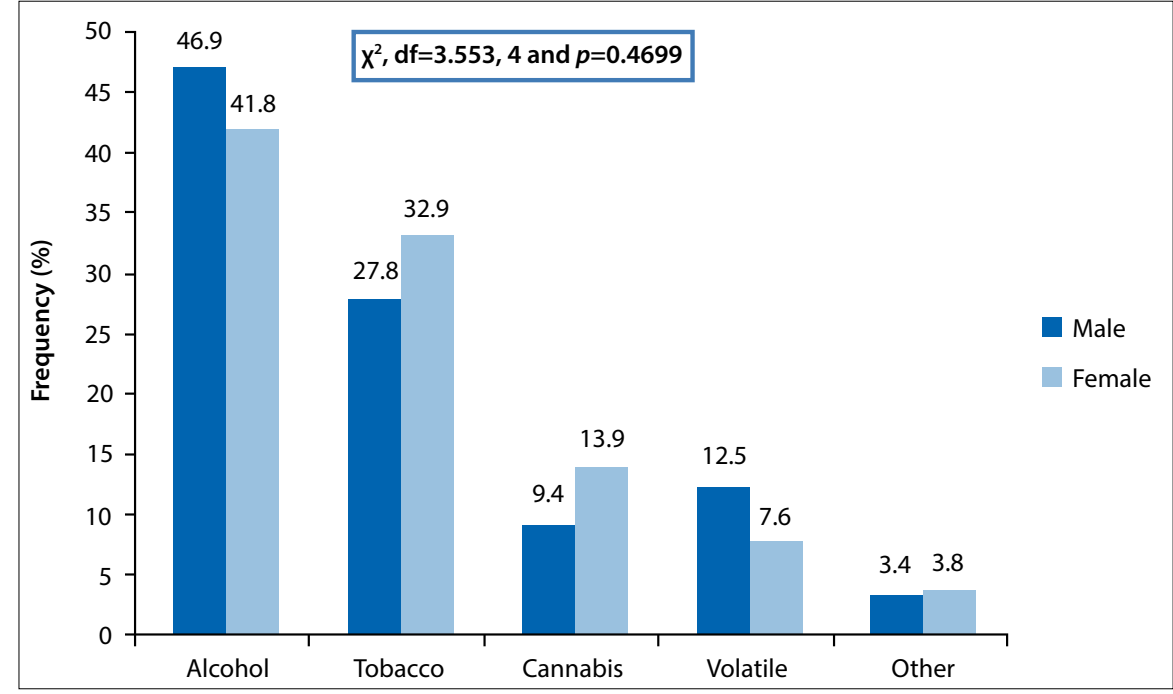

Fig. 2. Distribution of preferred psychotic substances by gender. for starting psychoactive substance use, the differences between the regions were not statistically significant $(p<0.36)$. Among

Table 1. Participant characteristics $(N=399)$

\begin{tabular}{ll}
\hline Variable & $\boldsymbol{n}(\%)$ \\
\hline City & \\
Bamenda & $125(31.3)$ \\
Douala & $137(34.3)$ \\
Yaoundé & $137(34.3)$ \\
Gender & \\
Boys & $320(80.2)$ \\
Girls & $79(19.8)$
\end{tabular}

Age group (years)

$12-14$

$15-17$ $310(77.6)$ 
all the participants, the main method of use was smoking (40.9\%), followed by drinking (34.3\%), chewing (10.5\%), sniffing (9.8\%) and swallowing $(4.5 \%)$. There were statistically significant differences $(p<0.000)$ in the main method of using psychoactive substance by region. Drinking, the second overall preferred method of ingesting the substances, was more popular in Yaoundé (40.9\%) and Douala $(39.4 \%)$ and less preferred in Bamenda (Table 2). With regard to the sources of the psychoactive substances, the majority of the participants mentioned that they bought them from roadside petty traders $(61.7 \%)$ across all the three cities, but more so in Douala compared with Yaoundé and Bamenda. Drug joints seemed to be the least preferred source of substances in Douala and Yaoundé, while bars/clubs were the least preferred supplier of substances in Bamenda (Table 2). There were statistically significant differences in the sources of the substances between the three cities $(p<0.007)$. Most of the participants were introduced to substance use by their street friends (80\%), particularly in Yaoundé and Douala, although some of them were introduced to substance use by their family members (14.4\%), a practice commonly observed in Bamenda as opposed to Douala and Yaoundé (Table 2). These sources of influence differed significantly in the three cities $(p<0.003)$.

\section{Pattern of substance abuse and related risky sexual behaviour and violence}

Among all 399 participants, 26.8\% reported engaging in prostitution after using drugs and/or consuming alcohol, with this pattern similarly observed in all three cities. Also, $55.4 \%$ of participants had experienced sexual abuse in the streets after using drugs or

Table 2. Regional comparisons of psychoactive substance (age of first use 12 - 13 years)

\begin{tabular}{|c|c|c|c|c|c|}
\hline & Total $(N=399), n(\%)$ & Bamenda $(n=125), n(\%)$ & Douala $(n=137), n(\%)$ & Yaoundé ( $n=137), n(\%)$ & $p$-value \\
\hline Reasons for first use & & & & & 0.36 \\
\hline Curiosity & $210(52.6)$ & $66(52.8)$ & $76(55.5)$ & $68(49.6)$ & \\
\hline Peer pressure & $111(27.8)$ & $34(27.2)$ & $31(22.6)$ & $46(33.6)$ & \\
\hline Emotional problem & $78(19.6)$ & $25(20.0)$ & $30(21.9)$ & $23(16.8)$ & \\
\hline Method of use & & & & & 0.00 \\
\hline Drinking & $137(34.3)$ & $27(21.6)$ & $54(39.4)$ & $56(40.9)$ & \\
\hline Smoking & $163(40.9)$ & $47(37.6)$ & $57(41.6)$ & $59(43.1)$ & \\
\hline Chewing & $42(10.5)$ & $18(14.4)$ & $13(9.5)$ & $11(8.0)$ & \\
\hline Sniffing & $39(9.8)$ & $25(20.0)$ & $8(5.8)$ & $6(4.4)$ & \\
\hline Swallowing & $18(4.5)$ & $8(6.4)$ & $5(3.7)$ & $5(3.7)$ & \\
\hline \multicolumn{6}{|l|}{ Source of procurement } \\
\hline Drug joints & $70(17.5)$ & $31(24.8)$ & $18(13.1)$ & $21(15.3)$ & 0.007 \\
\hline Bars/clubs & $83(20.8)$ & $29(23.2)$ & $20(14.6)$ & $34(24.8)$ & \\
\hline Roadside petty traders & $246(61.7)$ & $65(52.0)$ & $99(72.3)$ & $82(59.9)$ & \\
\hline Persons introducing & & & & & 0.003 \\
\hline Street friends & $319(78.0)$ & $86(68.8)$ & $116(84.7)$ & $117(85.4)$ & \\
\hline Casual acquaintance & $37(9.2)$ & $21(16.8)$ & $9(6.6)$ & $7(5.1)$ & \\
\hline Family member & $43(10.8)$ & $18(14.4)$ & $12(8.8)$ & $13(9.5)$ & \\
\hline
\end{tabular}

Table 3. Risky behaviours influenced by substance abuse

\begin{tabular}{|c|c|c|c|c|c|}
\hline Behaviour & Total $(N=399)$ & Bamenda $(n=125)$ & Douala $(n=137)$ & Yaoundé $(n=137)$ & $p$-value \\
\hline $\begin{array}{l}\text { Ever exchange sex for money after using drugs or } \\
\text { consuming alcohol, } n(\%)\end{array}$ & $107(26.8)$ & $32(26.6)$ & $40(29.2)$ & $35(25.6)$ & 0.740 \\
\hline $\begin{array}{l}\text { Ever experience sexual abuse in the streets after } \\
\text { using drugs or consuming alcohol, } n(\%)\end{array}$ & $221(55.4)$ & $78(62.4)$ & $66(48.2)$ & $77(56.2)$ & 0.117 \\
\hline $\begin{array}{l}\text { Ever had unprotected sex after using drugs or } \\
\text { consuming alcohol, } n(\%)\end{array}$ & $375(94.0)$ & $119(95.2)$ & $127(92.7)$ & $129(94.2)$ & 0.107 \\
\hline $\begin{array}{l}\text { Ever forced a girl to have sex after using drugs or } \\
\text { consuming alcohol, } n(\%)\end{array}$ & $67(16.8)$ & $13(10.4)$ & $38(27.7)$ & $16(11.7)$ & 0.000 \\
\hline $\begin{array}{l}\text { Used psychoactive substance and had forced sexual } \\
\text { intercourse with/(raped) a male/female, } n(\%)\end{array}$ & $120(30.1)$ & 77 (61.6) & $27(19.7)$ & $16(11.7)$ & 0.000 \\
\hline $\begin{array}{l}\text { Used any psychoactive substance but did not use } \\
\text { condom during last sexual intercourse, } n(\%)\end{array}$ & $306(76.7)$ & $80(64.0)$ & $116(84.7)$ & $110(80.3)$ & 0.006 \\
\hline $\begin{array}{l}\text { Been arrested by the police after using a } \\
\text { psychoactive substance, } n(\%)\end{array}$ & $225(56.4)$ & $59(47.2)$ & $112(81.8)$ & $54(39.4)$ & 0.000 \\
\hline
\end{tabular}


consuming alcohol, which was consistent in all three cities $(p<0.117)$ (Table 3). Furthermore, an overall majority of the participants (94.0\%) reported that they had unprotected sex (whether abused or not) after using drugs or consuming alcohol. The above practice was witnessed in all three cities with no statistical differences in their frequencies $(p<0.107)$. A considerable proportion of the participants admitted to having been raped/suffered forced sexual intercourse with a boy or girl after using a psychoactive substance (30.0\%), with slight differences observed between the regions (Table 3). The majority of the participants (76.7\%) reported that they did not use condoms while under the influence of alcohol or drugs. This risky sexual behaviour was more prevalent in Douala (84.7\%) and Yaoundé $(80.3 \%)$ than in Bamenda (64\%), showing statistically significant differences $(p<0.006)$. More than $70 \%$ of the participants mentioned that they had been involved in a fight after using psychoactive substances, with this behaviour being slightly more pronounced among boys than girls $(p<0.495)$. However, almost $90 \%$ of the girls mentioned that they had previously engaged in sex work to survive, compared with only a handful of boys $(p<0.000)$.

\section{Discussion}

The study interviewed 399 (320 male and 79 female) street children, all of whom admitted to using psychoactive substances while on the streets. Other studies in Nigeria and India also reported that $>70 \%$ of street children were abusing psychoactive substances. ${ }^{[2,3]}$ Further studies have showed that more boys than girls abuse psychoactive substances. A reason could be that there are more street boys than girls in urban cities and because boys are more exposed to risky behaviour than girls, particularly in most African countries. ${ }^{[2,6,8]}$

This study found that curiosity, peer pressure and emotional problems were the main reasons for children engaging in psychoactive substance abuse. Similar findings were reported in some African studies. ${ }^{[4,5]}$ Other reasons such as 'courage and confidence to face and forget the hardships encountered on the streets', and 'a coping strategy when feeling sick or depressed' have also been reported. ${ }^{[3,5]}$ These reasons are not similar to studies of psychoactive substance abuse conducted with non-street children. Children under proper adult supervision are more likely to abuse substances because of peer pressure. ${ }^{[4,7]}$ The majority of street children cited alcohol as the preferred psychoactive substance, followed by tobacco. The most preferred methods of ingesting the substances into their system were by drinking and smoking, and these results were the same across all three regions. A study in Nigeria also produced similar results of abusing mostly alcohol and tobacco ${ }^{[5]}$ Slightly different results have been reported in another study in Nigeria and in Egypt on street children. Both studies reported a high prevalence in the abuse of other psychoactive substances such as glue, benzene, petrol and paint because of their availability (children buy from supermarkets, retailers and street vendors at a much cheaper price). They can become addicted to these substances after a certain period of frequent use. ${ }^{[5,11]}$ Significant differences were reported among street/homeless youths in developed countries, where they inject the drugs into their system, placing them at direct risk of several health problems ${ }^{[1,7]}$ The global differences could also be attributed to the inequality around access and the socioeconomic status of the respective participants in developing and developed countries. More than $60 \%$ of the participants identified roadside petty traders (street vendors) as their main supplier of psychoactive substances, raising questions regarding the regulation of informal trading to minors in Cameroon. ${ }^{[13]}$ Similar negligence in policy implementation is common in most LMICs. Some traders are not even aware that selling psychoactive substances to a minor is a crime punishable by law. ${ }^{[8,9]}$ However, a completely different result was reported in a study in South Africa (SA), where street children have reported seeking assistance from adults to buy them psychoactive substances from supermarkets and other roadside shops. This is so because it is illegal and punishable by law to sell alcohol, tobacco and other harmful substances to minors, a policy which is generally known by shop owners. However, implementation is not $100 \%$ as some traders are more interested in making money than respecting state policies. ${ }^{[6,7]}$

Regional comparisons reveal some unexpected differences between the three cities of Bamenda, Douala and Yaoundé in Cameroon. The percentage of sniffers was high in Bamenda, possibly because of the easy access to sniffers from surrounding villages, and because it is still a culturally accepted practice by the elderly in the community. Douala had the highest percentage of participants accepting sexual intercourse without condoms and being arrested by the police. This could be because Douala is a city characterised by diverse business enterprises, while Yaoundé is a political capital dominated by administrative activities with high-class dignitaries. In comparison with both cities, Bamenda is a laid-back city known for multicultural activities and political uprising from opposition party leaders.

Results from this study also showed that most of the street children were initiated into abusing psychoactive substances by their peers on the streets. Another study from Cameroon and results from a literature review on street children in Africa also reported similar results. ${ }^{[12,13]}$ It is common knowledge that abuse of these substances is harmful and deadly when ingested into the system, and that risky behaviours by street children can lead to health and social problems. The association between smoking and tuberculosis/lung cancer is well documented. ${ }^{[14]}$ The abuse of psychoactive substances also puts street children at further risk owing to their frequent involvement in crime, violence, rape, sexual abuse and unprotected sex, which could lead to police arrest, injuries, emotional trauma, unwanted pregnancies, STDs and HIV infections. ${ }^{[1,4]}$ Studies elsewhere have documented the link between HIV/AIDS and substance abuse. ${ }^{[1,14]}$ SA and other countries in sub-Saharan Africa are noted for violence, gender-based violence, rape, sexual abuse and HIV/AIDS.The above behaviours of street children would simply further perpetuate the public health concerns ${ }^{[4,6,14]}$ However, in SA, the use of a concoction of very harmful drugs (such as rat poison combined with HIV treatment drugs), encourages behaviours such as rape and horrific killings. ${ }^{[6]}$ Some of these dangerous behaviours were sadly revealed in our study, where the majority of participants agreed to have been involved in violence, rape or forced sexual intercourse, sex work and having unprotected sex. Collaboration and immediate interventions by all stakeholders will be the best strategy to help reduce the number of street children in urban cities, thereby protecting them from abusing psychoactive substances. There is a need for formal and health education about the dangers of living on the streets and abusing psychoactive substances. Early detection through the screening of street children who are addicted to any of the psychoactive substances should be introduced by social workers and other organisations. Because of the complexity of the problem of street children, the involvement of all stakeholders will be necessary for intervention and rehabilitation to be sustainable and affordable. The authors urge the Cameroon government to consider improving the lives of children and families generally in a bid to avoid increasing numbers of children leaving their homes and taking to the streets. All the stakeholders involved with street children should work together and act urgently to address the poverty and challenges these children face while on the streets in urban cities. They should ensure that access to harmful substances is banned for unlicensed traders and enforce strict regulations for street traders selling psychoactive substances in order to stop the trade with minors.

\section{Conclusion}

Children living on the streets and engaging in psychoactive substance abuse is a problem in all three cities studied in Cameroon. Initiation into psychoactive substances was by peers, while addiction to any harmful substance was a direct result of the amount of time they have 
been living on the streets. Abuse was more prevalent among boys than girls. Street children mostly use alcohol and tobacco because it is cheap and available from roadside traders. These are important factors that should be taken into consideration when designing public health policies for street children. Immediate intervention and rehabilitation for these children is needed.

\section{References}

1. Akinade EA. Risk-taking behavior and substance abuse vis-a-vis HIV transmission in African societies. J Instruct Psychol 2001;28(1):3.

2. Morakinyo J, Odejide AO. A community based study of patterns of psychoactive substance use among street children in a local government area of Nigeria. Drug Alcohol Depend 2003;71(2):109-116. DOI:10.1016/s0376-8716(03)00093-0

3. Seth R, Kotwal A, Ganguly KK. Street and working children of Delhi, India, misusing toluene: An ethnographic exploration. Subst Use Misuse 2005;40(11):1659-1679. DOI:10.1080/10826080500222792

4. Woolf-King SE, Maisto SA. Alcohol use and high-risk sexual behavior in sub-Saharan Africa: A narrative review. Arch Sex Behav 2011;40(1):17-42. DOI:10.1007/s10508-009-9516-4

5. Morantz G, Cole D, Vreeman R, Ayaya S, Ayuku D, Braitstein P. Child abuse and neglect among orphaned children and youth living in extended families in
sub-Saharan Africa: What have we learned from qualitative inquiry? Vulnerable Child Youth Stud 2003;8(4):338-352. DOI:10.1080/17450128.2013.764476

6. Pluddemann A, Parry C, Cerff P, et al. Monitoring alcohol and drug abuse trends in South Africa. Drug Alcohol Rev 2008;2:185-189.

7. World Health Organization. Management of Substance Abuse. Geneva: WHO, 2008 http//www who int/substance abuse/en/2008 (accessed 12 September 2013).

8. Nada KH, Suliman el DA. Violence, abuse, alcohol and drug use, and sexual behaviors in street children of Greater Cairo and Alexandria, Egypt. AIDS 2010;24(2):S39-S44. DOI:10.1097/01.aids.0000386732.02425.d1

9. Ennew J. Difficult circumstances: Some reflections on street children in Africa. Africa Insight 1996;26(3):203-210.

10. Elkoussi A, Bakheet S. Volatile substance misuse among street children in Upper Egypt. Subst Use Misuse 2011;46(1):35-39. DOI:10.3109/10826084.2011.580202

11. Nada KH, Suliman el DA. Violence, abuse, alcohol and drug use, and sexual behaviors in street children of Greater Cairo and Alexandria, Egypt. AIDS 2010;24:S39-S44. DOI:10.1097/01.aids.0000386732.02425.d1

12. UNICEF. Street and unsupervised children of Africa, 2003. http://www.unicef org/Africa/street_children_Report_Eng.pdf (accessed 30 April 2015).

13. Matchinda B. The impact of home background on the decision of children to run away: The case of Yaounde City street children in Cameroon. Child Abuse Negl 1999;23(3):245-255. DOI:10.1016/S0145-2134(98)00130-6

14. Odejide AO. Status of drug use/abuse in Africa: A review. Int J Ment Health Addict 2006;4(2):87-102. DOI:10.1007/s11469-006-9015-y 